\title{
Quiz
}

CORReCt ANSWER TO THE QUiz. CHeCK YOUR DIAGNOSIS

\section{CASE REPORT}

\section{SYNOVIAL SARCOMA OF THE STOMACH: CASE REPORT AND SYSTEMATIC REVIEW OF THE LITERATURE}

\author{
Martyna Krupińska ${ }^{1}$, Ewa Kaznowska ${ }^{2}$, Anna Kruczak ${ }^{1}$, Katarzyna Mularz ${ }^{1}$, \\ Agnieszka Adamczyk ${ }^{1}$, Jaroseaw Deugosz ${ }^{3}$, Józef Gancarz ${ }^{4}$, Janusz Ryś ${ }^{1}$
}

\author{
${ }^{1}$ Department of Tumor Pathology, Maria Sklodowska-Curie National Research Institute of Oncology, Krakow Branch, \\ Poland \\ ${ }^{2}$ Department of Pathology Institute of Medical Sciences, Medical College of Rzeszow University, Rzeszow, Poland \\ ${ }^{3}$ Department of Surgical Oncology, Specialist Hospital, Podkarpacki Oncology Center in Brzozow, Poland \\ ${ }^{4}$ Department of Radiology and Imaging Sciences, Specialist Hospital, Podkarpacki Oncology Center in Brzozow, Poland
}

\begin{abstract}
Synovial sarcoma is a rare mesenchymal malignant neoplasm that presents a specific $\mathrm{t}(\mathrm{X} ; 18)$ translocation forming SS18(SYT)-SSX chimera gene. It is most commonly seen in soft tissues of the extremities. The digestive tract is an exceptional site of involvement. We report a case of primary gastric synovial sarcoma in a 48-year-old female. Differential diagnosis of synovial sarcoma from other spindle cell, mesenchymal and cytokeratin-positive tumors is critical for the treatment and prognosis. Immunohistochemistry studies and molecular analysis are required to settle a proper diagnosis.
\end{abstract}

Key words: synovial sarcoma, stomach, spindle cell neoplasm, cytokeratin.

\section{Introduction}

Synovial sarcoma is a rare mesenchymal malignant neoplasm, accounting for about $10 \%$ of soft tissue sarcomas. It is most commonly seen in soft tissues of the extremities, however, cases with unusual locations such as head and neck, lung and mediastinum, abdomen and retroperitoneum, kidney, among others, have been reported $[1,2]$. Although the gastrointestinal tract is an extremely rare location for synovial sarcoma, this type of presentation has also been previously described and the stomach is the most frequent location along the digestive tract. To the best of our knowledge, only 36 primary gastric synovial sarcoma cases have been reported in the English literature [3-20]. We present an additional case of primary gastric synovial sarcoma in a 48-year-old female. 


\section{Case report}

The patient was a 48 -year-old female who presented at Specialist Hospital and Podkarpacki Oncology Center in Brzozow with nonspecific upper abdominal pain and intermittent nausea that had continued for a few months.

A CT scan of the abdominal cavity of the patient demonstrated extensive thickening of the wall of the pyloric region of the stomach (Fig. 1), but there was no other site indicating primary or metastatic lesions. A biopsy specimen, obtained during upper gastrointestinal endoscopy, revealed proliferation of atypical spindle cells positive for cytokeratin and negative for CD117, CD34 and SMA. According to the results, a GIST diagnosis was rejected and a suspicion of poorly differentiated carcinoma was made. Regarding the lesion size the patient received neoadjuvant chemotherapy. During surgery, a gastric tu-

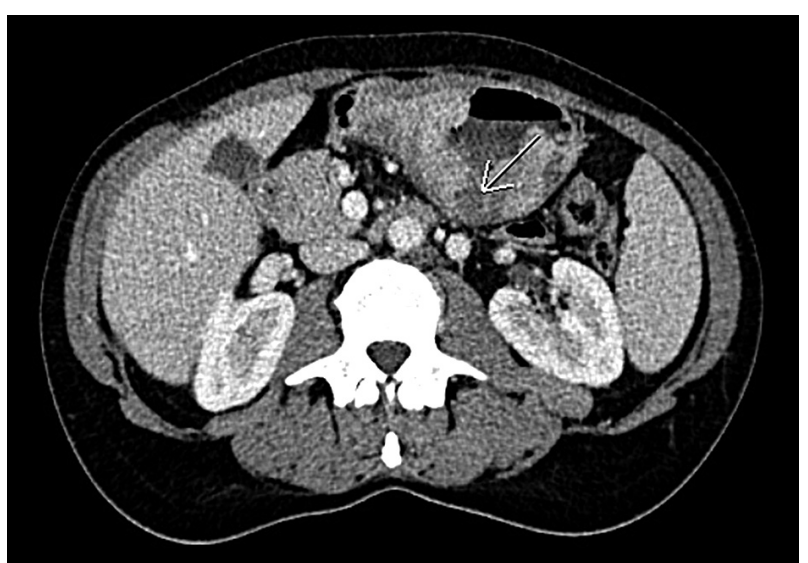

Fig. 1. CT scan of the abdominal cavity showing the location of the tumor mor measured $9 \times 8 \times 3 \mathrm{~cm}$ was found. It involved the distal part of the body and the pyloric region of the stomach. The stomach was resected and both macroscopic and histological examination of the surgical specimen showed diffuse neoplastic infiltration covering the full thickness of the stomach wall (Fig. 2) and passing to the surrounding adipose tissue.

\section{Material and methods}

Immunostaining was performed for cytokeratins, EMA, Bcl2, SMA, Desmin, Vimentin, S100, CD31, CD34, CD117, CD99, SOX10 and HMB45. All immunohistochemistry was done on $4-\mu \mathrm{m}$-thick, standard-size sections, which were first dewaxed, rehydrated, and blocked for endogenous peroxidase (with 3.0\% hydrogen peroxide). Details of primary antibodies, their dilutions, pretreatments, and sources used in the study are depicted in Table I.

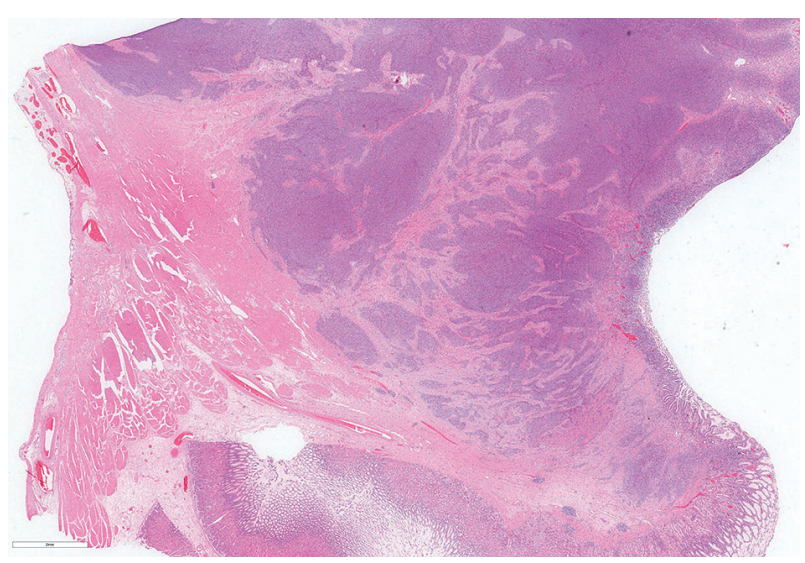

Fig. 2. The scan of the haemantoxylin and eosin (HE) staining slide covering the full cross-section of the stomach wall

Table I. Primary antibodies, their dilutions, pretreatments, and sources used in this study

\begin{tabular}{|c|c|c|c|c|}
\hline ANTIGEN & ANTIBODY CLONE(s) & Dilution & Pretreatment & SOURCE OF ANTIBODY \\
\hline Cytokeratins & AE1/AE3 cocktail & $1: 600$ & Citrate buffer - heat & Cell Marque \\
\hline EMA & GP1.4 & $1: 200$ & None & Leica Biosystem \\
\hline $\mathrm{Bcl} 2$ & 124 & $1: 100$ & Citrate buffer - heat & Cell Marque \\
\hline SMA & OCSM-1 & $1: 50$ & None & DAKO Cytomation \\
\hline Desmin & DE-R-11 & $1: 100$ & Citrate buffer - heat & Leica Biosystem \\
\hline $\mathrm{S} 100$ & polyclonal & $1: 600$ & Trypsin $15 \mathrm{~min}$ & Leica Biosystem \\
\hline CD31 & $1 \mathrm{~A} 10$ & $1: 50$ & Citrate buffer - heat & Leica Biosystem \\
\hline $\mathrm{CD} 34$ & QBEnd/10 & $1: 50$ & Trypsin $15 \mathrm{~min}$ & Leica Biosystem \\
\hline CD117 (KIT) & A4502 & $1: 400$ & Citrate buffer - heat & DAKO Cytomation \\
\hline CD99 & EPR30974 & $1: 100$ & Citrate buffer - heat & Cell Marque \\
\hline SOX 10 & $\mathrm{~N}-20$ & $1: 100$ & Citrate buffer - heat & Santa Cruz Biotechnology \\
\hline HMB 45 & HMB 45 & $1: 80$ & Citrate buffer - heat & Thermo Scientific \\
\hline Vimentin & V9 & $1: 250$ & Citrate buffer - heat & Cell Marque \\
\hline
\end{tabular}


Interphase fluorescent in situ hybridisation (FISH) was performed on $5 \mu \mathrm{m}$ paraffin-embedded tissue sections using the LSI SS18 (18q11.2) Dual Color Break Apart Rearrangement Probe set (Vysis, Downers Grove, IL, USA). Hybridisation was performed according to the manufacturer's protocol. Slides were mounted and counterstained with anti-fade DAPI (Vysis, Downers Grove, IL, USA), visualized using an epifluorescent Microscope (Olympus BX61). At least 300 interphase nuclei were analyzed.

\section{Results}

Microscopically, HE slides showed monotonous histological texture built predominantly of spindle-shaped cells forming herring-bone or fibrosarcoma-like fascicles (Fig. 3). These spindle neoplastic cells were relatively small and uniform in size with fusiform or ovoid nuclei and a small or inconspicuous nucleoli. Their cytoplasm was scant and the cell borders were indistinct. Focally, the additional component made of epithelioid or small round cells have been also noticed (Fig. 4). Both spindle cells and the epithelioid or small round cells created focal hemangiopericytoma-like (Fig. 5) arrangements or formed solid sheets separated by fibrous or myxoid stroma (Fig. 6). Mitotic figures were readily identified with at least 7 figures per 10 high-power fields. The tumor stroma showed varying degrees of thin-walled dilated and/or staghorn-shaped blood vessels, thereby imparting a hemangiopericytoma-like growth pattern.

Immunohistochemically, the tumor cells were strongly positive for cytokeratins (AE1/AE3) (Fig. 7), EMA, vimentin (Fig. 8) and $\mathrm{Bcl} 2$ antigen (Fig. 9), but did not present reaction against smooth muscle actin, S100 protein, CD20, HMB45, SOX10, CD31, CD34, CD99 and CD117.

Rearrangement of the SS18(SYT) gene (18q11.2) was detected by dual-color break-apart fluorescent in situ hybridization analysis of the SS18(SYT) locus on an interphase cell nuclei (Fig. 10).
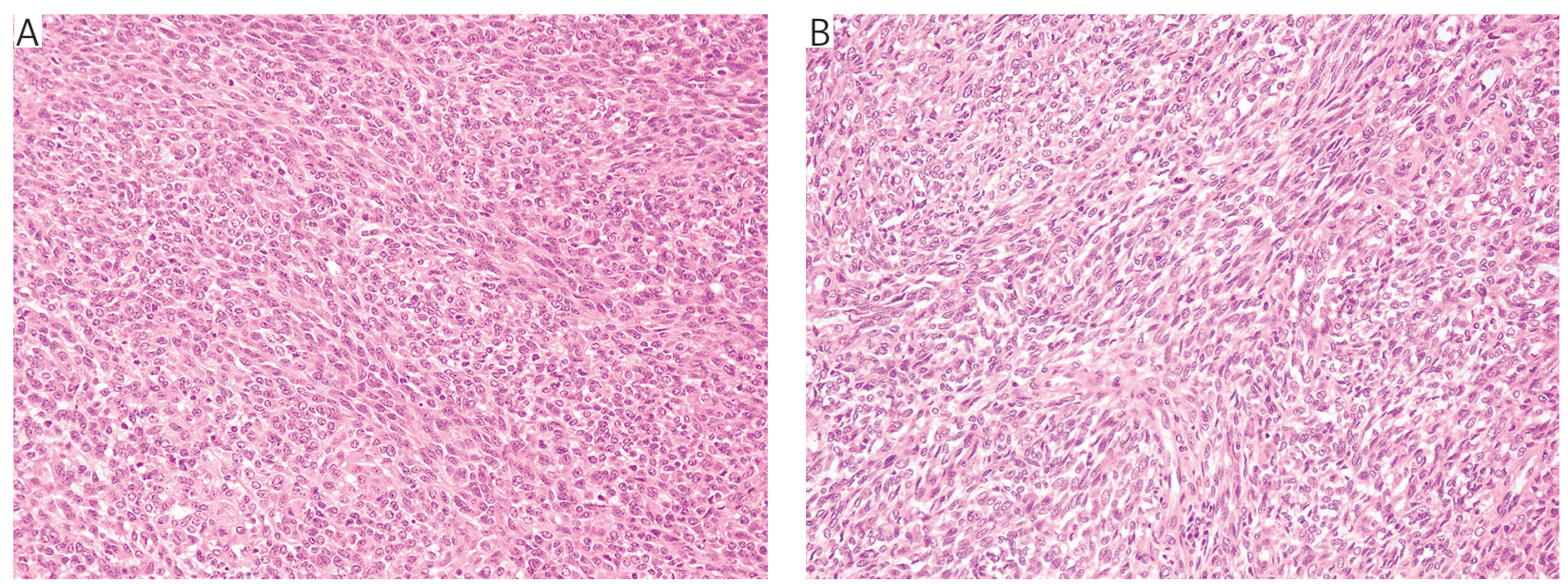

Fig. 3. A, B) Intersecting fascicles of the spindle cells in a herring-bone pattern (HE)

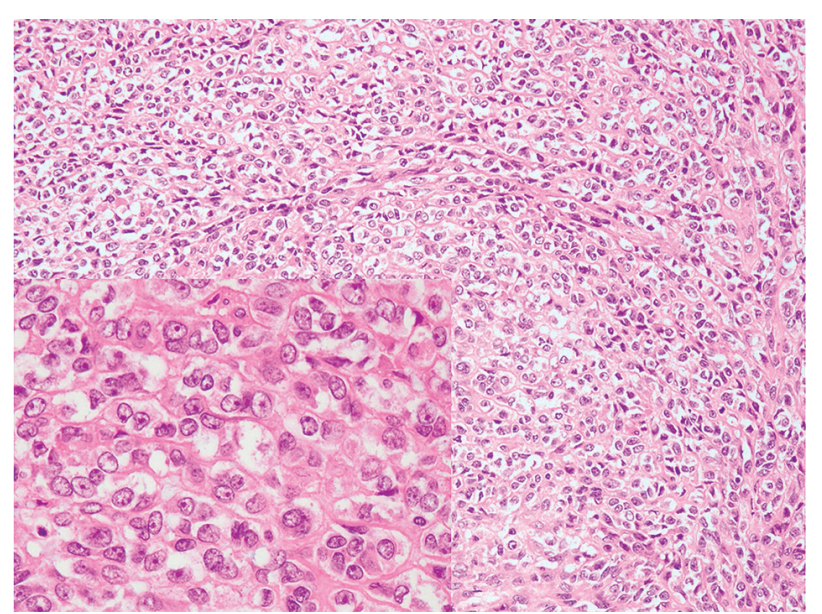

Fig. 4. Short spindle cell or epithelioid cell (insert) component of the tumor (HE)

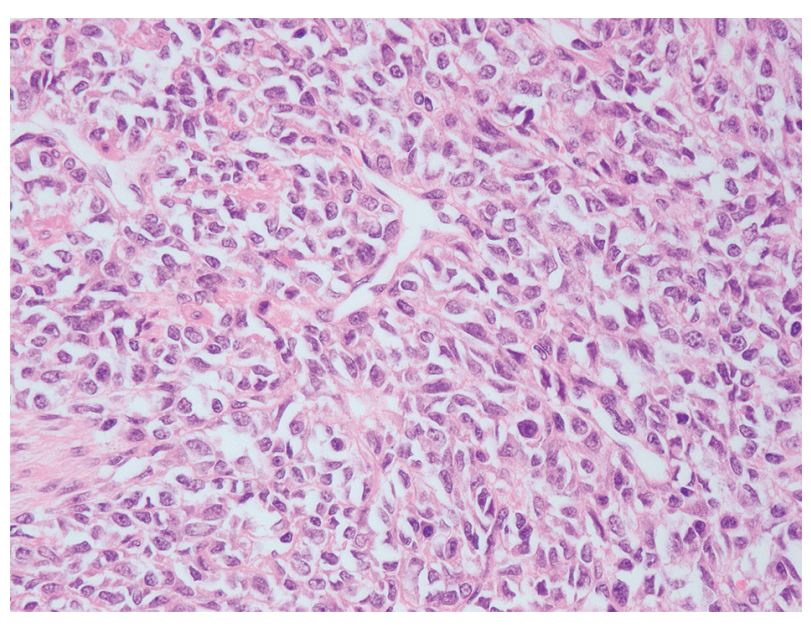

Fig. 5. Short spindle or small round cells creating hemangiopericytoma-like texture (HE) 


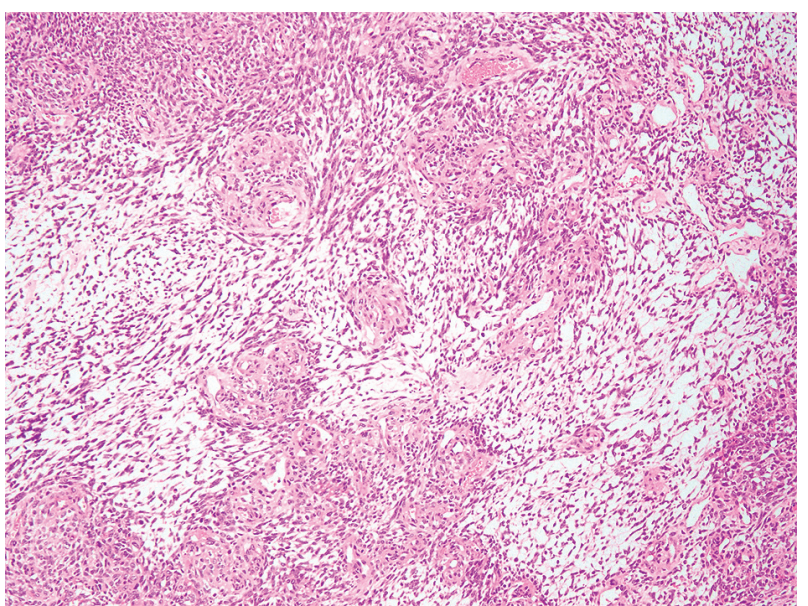

Fig. 6. Solid sheets of neoplastic cells separated by myxoid stroma $(\mathrm{HE})$

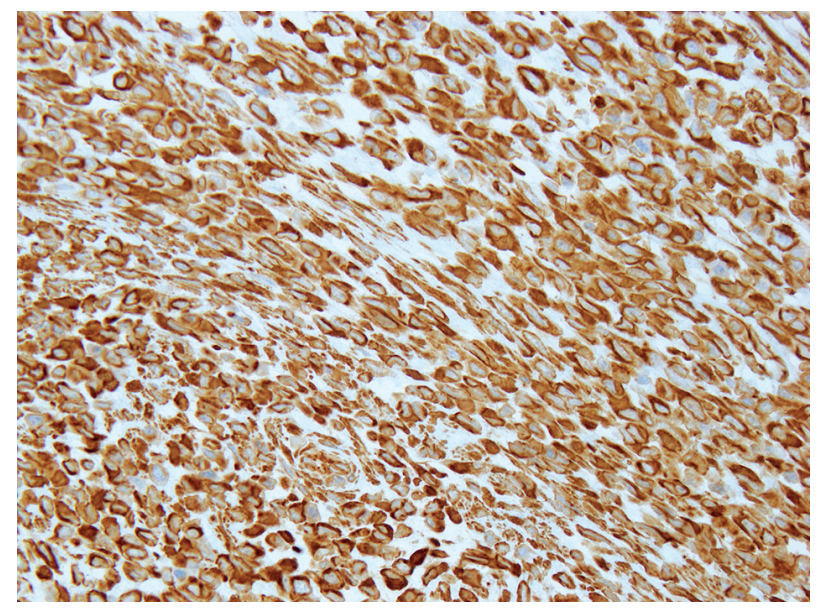

Fig. 8. Immunohistochemical staining for vimentin

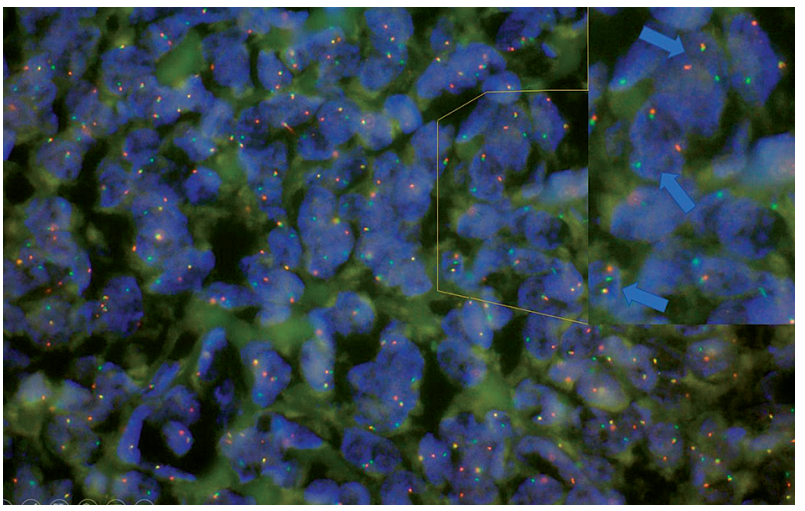

Fig. 10. FISH using $S S 18(S Y T)$ break-apart probe set showed the split of two signals in most of the nuclei (original $1000 \times$ magnification)

\section{Discussion}

Synovial sarcoma (SS) can occur in many different locations throughout the body and is rarely found within the gastrointestinal tract. The first report con-

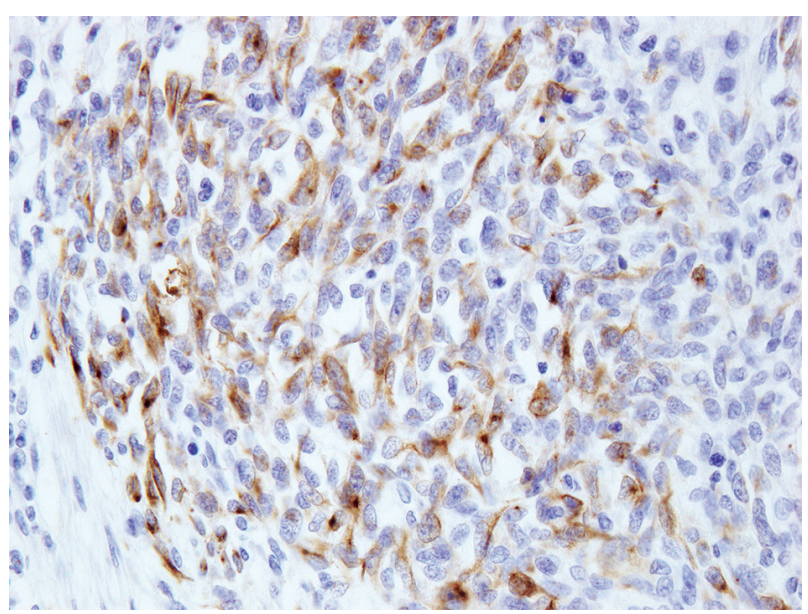

Fig. 7. Immunohistochemical staining for cytokeratins (AE1/AE3)

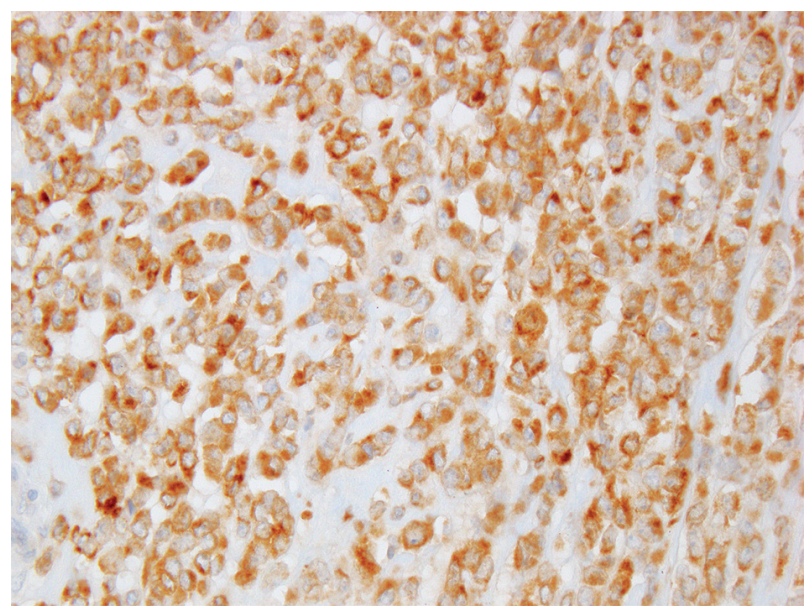

Fig. 9. Immunohistochemical staining for $\mathrm{Bcl} 2$

cerning primary gastric SS was published in 2000 by Billings et al. [3]. The last two cases were reported by Manohar et al. [19] and Wong et al. [20] in 2020. The clinicopathological features of the 37 cases of primary gastric SS, including our case, are summarized in Table II.

Similarly to synovial sarcomas at other sites, gastric SS occur mostly in middle-aged patients with a median age of 47 years (range 13 to 68 years); there is a slight prevalence of males than females (19/18). The mean/median age of male and female patients is 40/42 (range from 13 to 62) and 51/50 (range from 35 to 68) years, respectively. The gastric body and fundus are the most common locations, but tumors localized in the gastroesophageal junction, cardia, antrum, and gastroduodenal junction have also been reported.

The tumor size ranged from 0.8 to $16 \mathrm{~cm}$ (median $4.35 \mathrm{~cm}$ ). Most of the lesions were ulcerated. Ten tumors were transmural masses infiltrating adjoining 


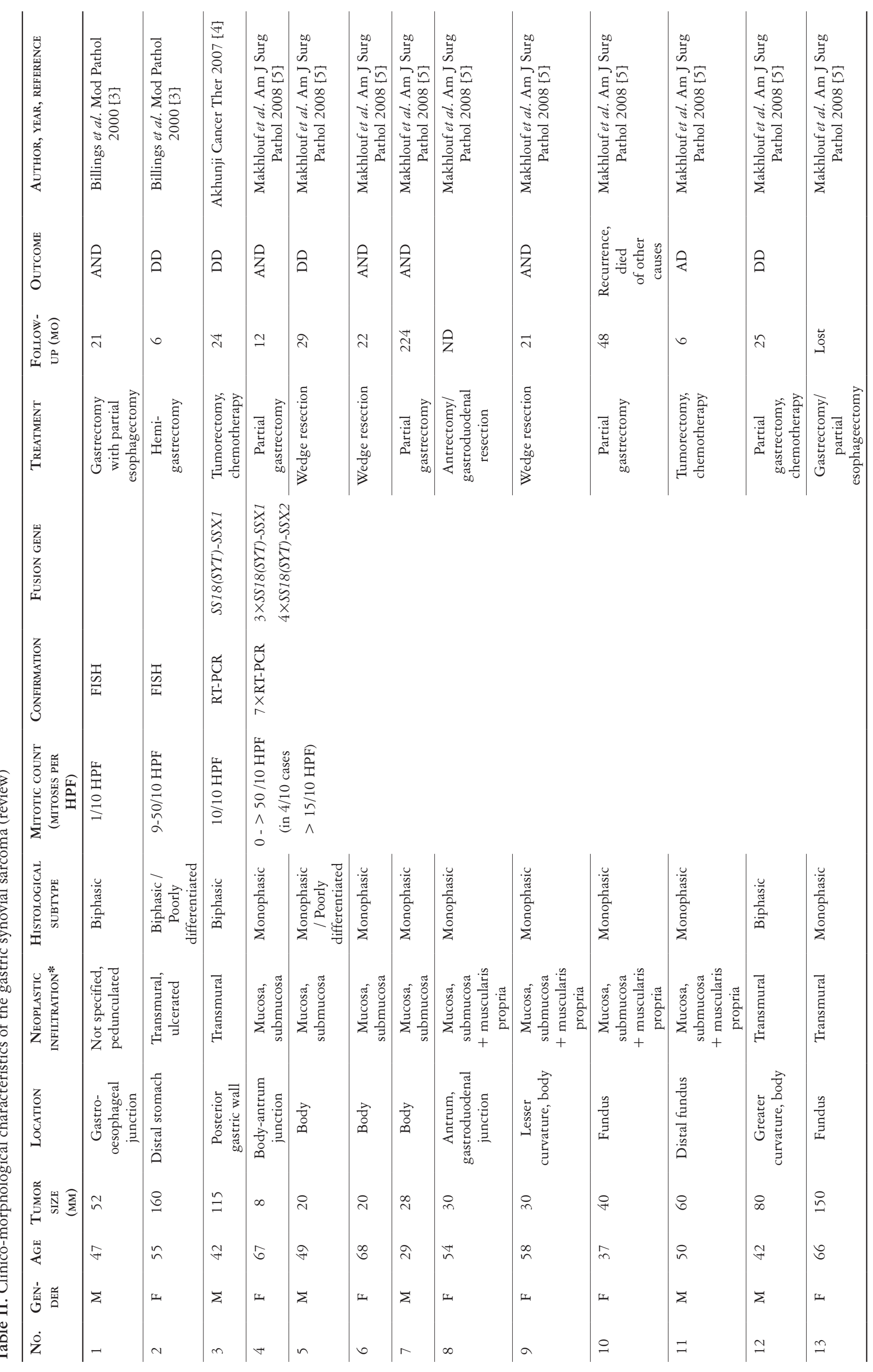




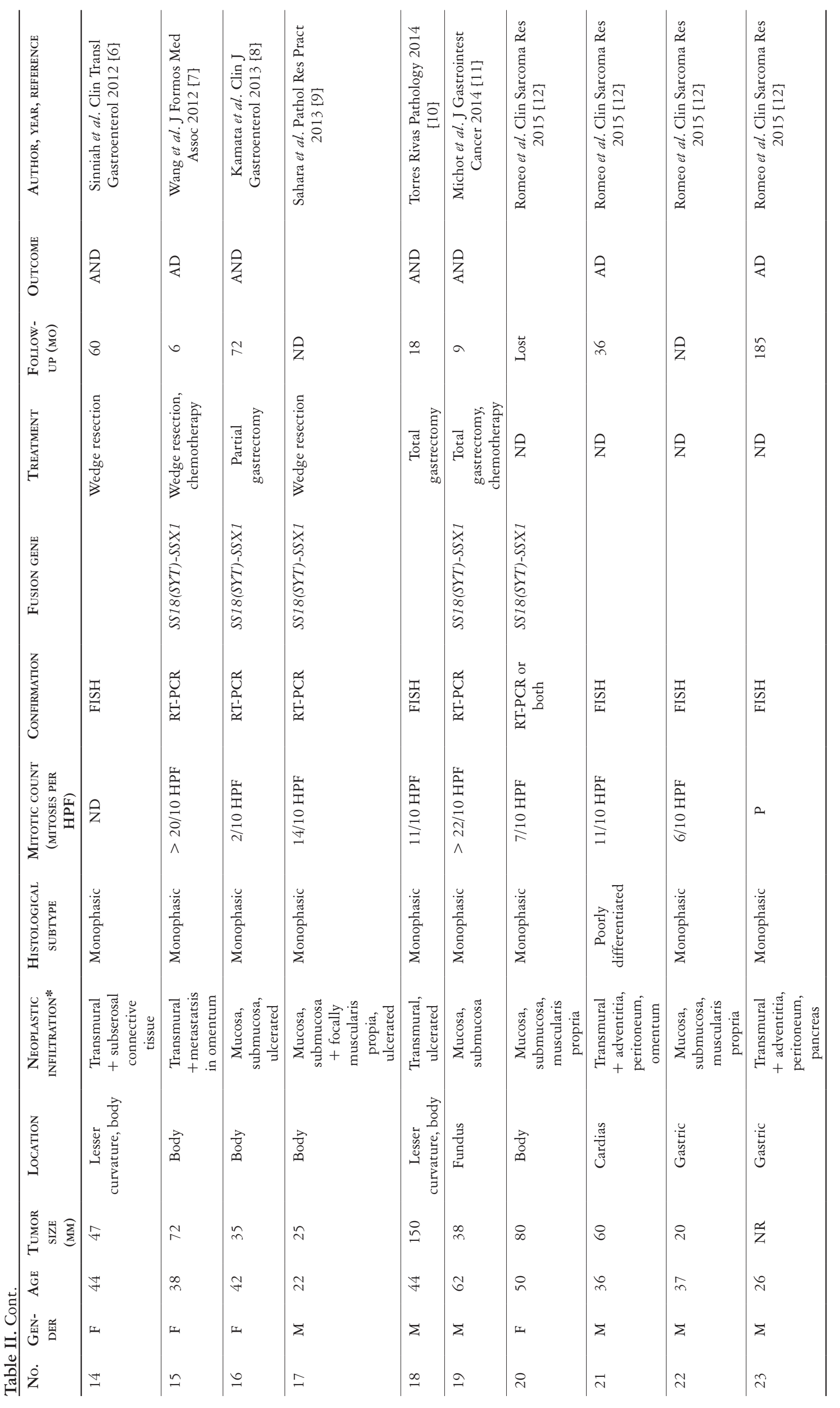




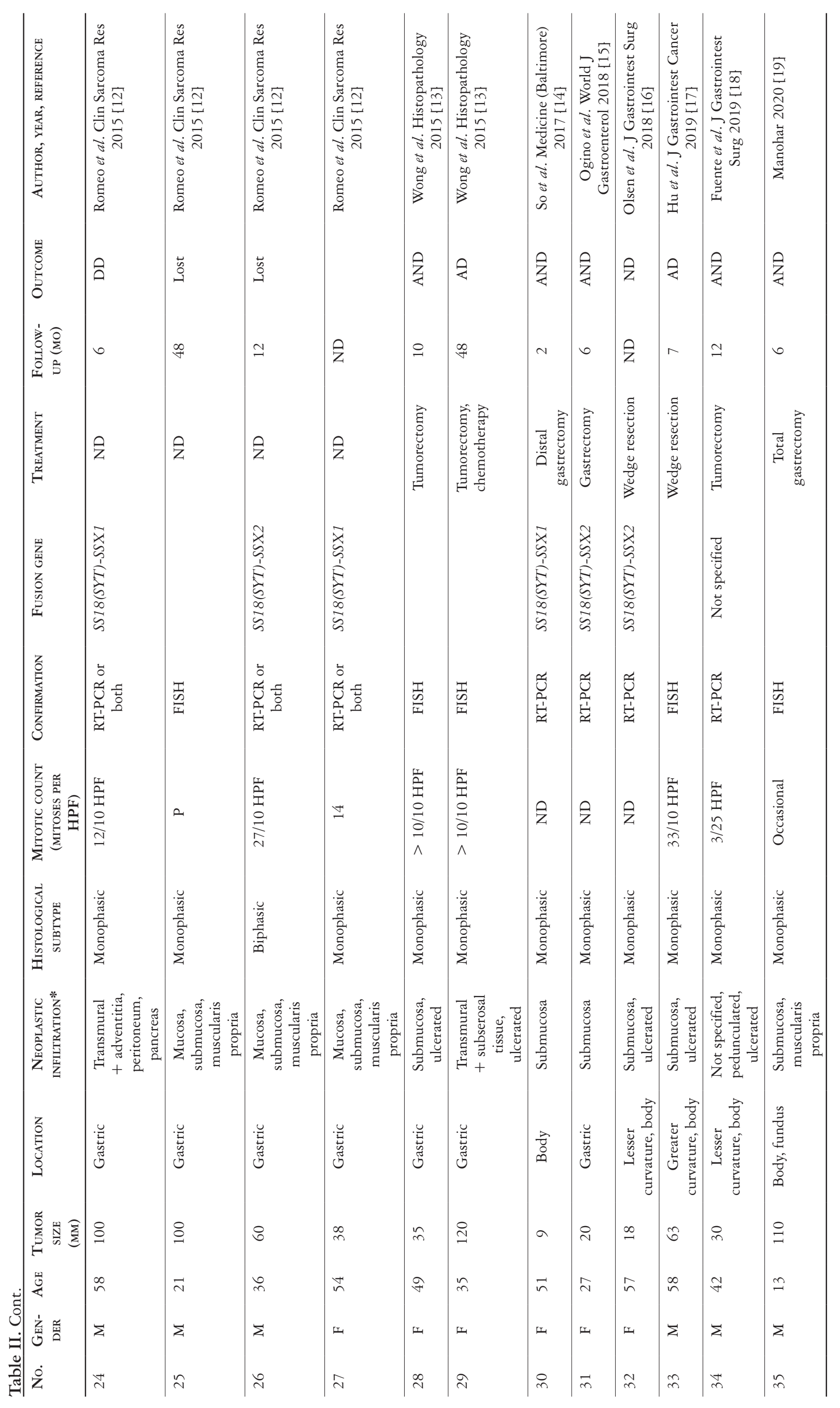


tissues and the other twenty-seven were intramural and predominantly involving the luminal side.

Histologically gastric SS presents similar microscopy characteristics to other locations. There are three classically defined microscopic variants: biphasic, monophasic and poorly differentiated. Among 37 tumors reported in the English literature (including our case) there were thirty cases of monophasic fibrous SS, four cases classified as biphasic subtype and other three cases with at least focal poorly differentiated component. Mitoses per $10 \mathrm{HPF}$ ranged from 0 to over 50 .

The immunohistochemical studies of this neoplasm have been varied, although determination of expression of wide spectrum cytokeratin was constant, obtaining positive results in all, except two reported cases (25/27). EMA, TLE1, CD56, Bcl2 and vimentin were positive in all tested cases. On the contrary, CD34, S100, SMA, and desmin were consistently negative (Tables III, IV). Almost all of the previously described gastric synovial sarcomas did not express CD117. The only exception were two cases presented by Wong et al. [13]. Two gastric synovial sarcomas from their collection showed a weak reaction to both CD117 and DOG1. However, no activating mutations were detected in KIT exons 9, 11,13 and 17 or PDGFRA exons 12, 14 and 18 in any of these cases.

Therefore, a confident distinction between abdominal synovial sarcoma and GIST requires KIT/ PDGFRA mutation analyses and specific molecular testing for synovial sarcoma. Most synovial sarcoma cases have a reciprocal translocation between the short arm of chromosome $\mathrm{X}$ and the long arm of chromosome 18. This translocation fuses the SSX1 or SSX2 genes from chromosome $\mathrm{X}$ and the SS18(SYT) gene from chromosome 18 to form SS18(SYT)-SSX chimera gene. The most reported gastric synovial sarcomas were molecularly confirmed by interphase FISH (14/37) or RT-PCR (20/37). Of 20 cases examined by RT-PCR at least two were simultaneously studied by FISH using SS18(SYT) break-apart probes [9, 12]. SS18-SSX1 and SS18-SSX2 fusion genes were demonstrated in 12 and 7 cases, respectively. In one case the fusion product was not specified [18].

Monophasic SS in the gastric wall should additionally be discerned from other mesenchymal tumors, including leiomyoma, leiomyosarcoma, schwannoma, solitary fibrous tumor, and "gastroblastoma" a distinctive biphasic (epithelio-mesenchymal) tumor of the stomach in young adults [21], as well as other cytokeratin-positive tumors such as poorly differentiated carcinoma, and sarcomatoid carcinoma.

A diagnosis of synovial sarcoma should be considered particularly if an abdominal spindle cell neo- 


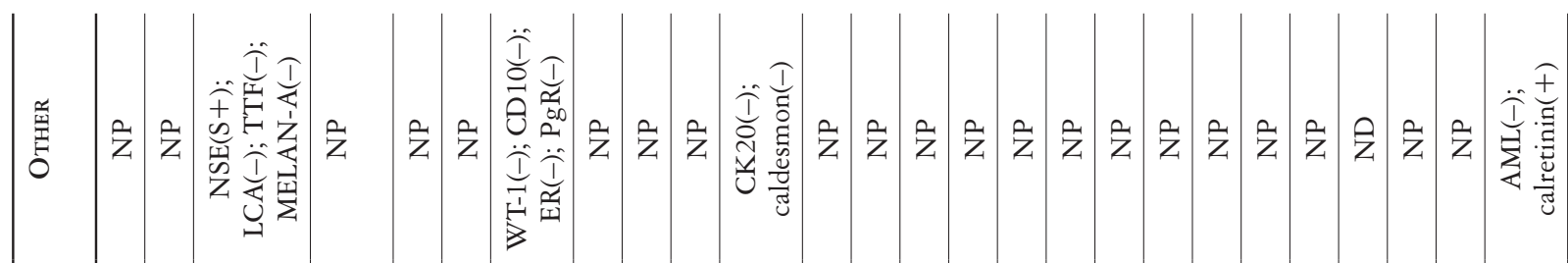

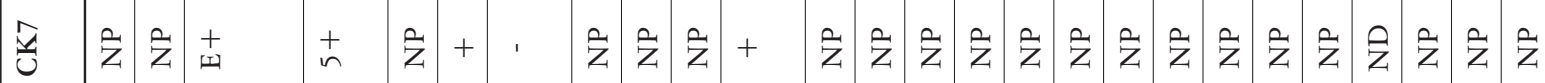

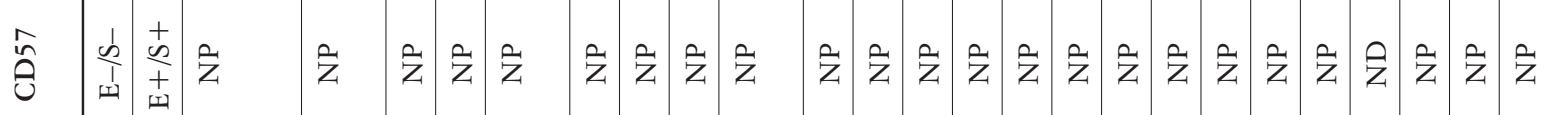

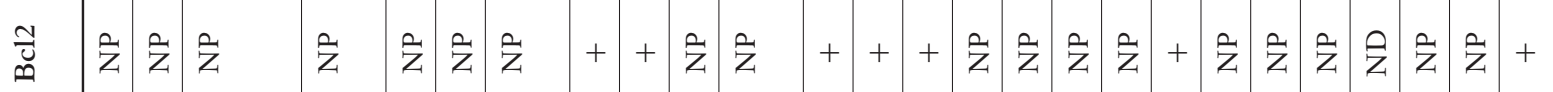

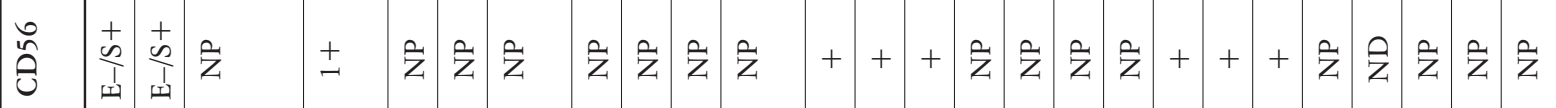
苑苂令1 兽

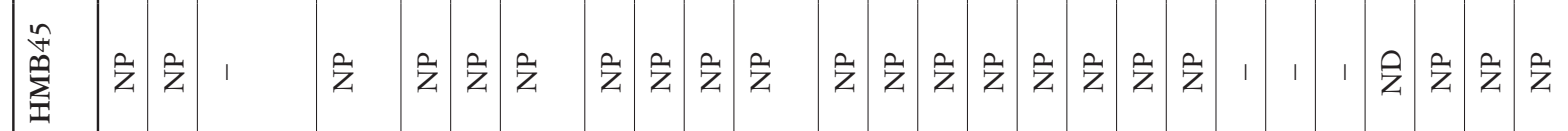

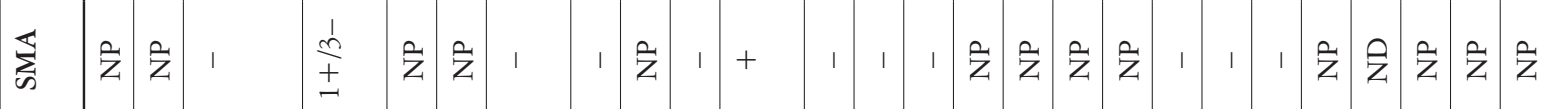

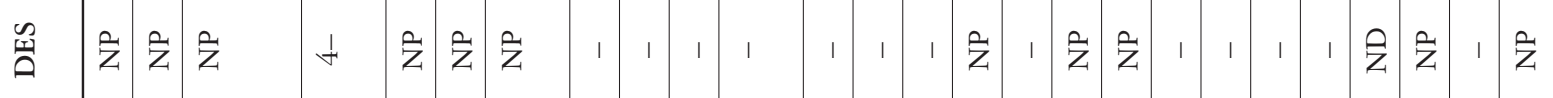

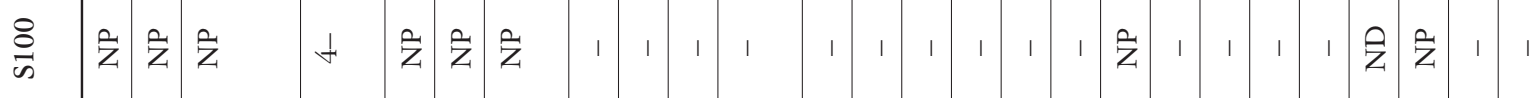

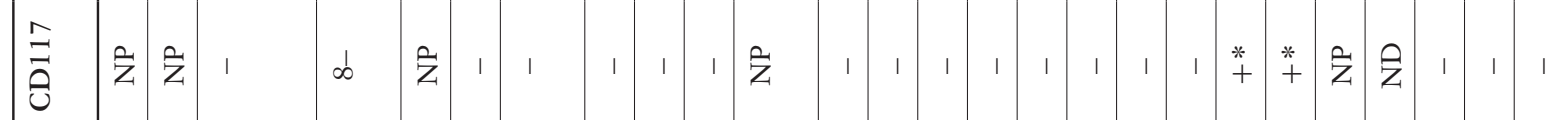

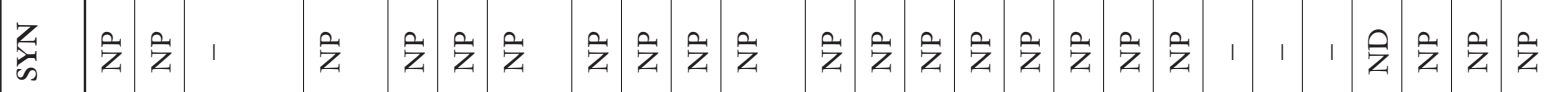

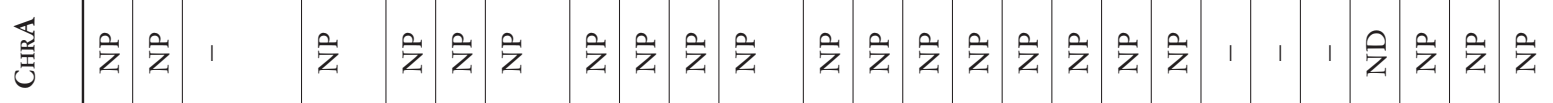

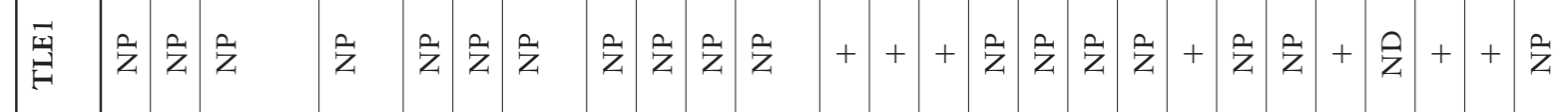

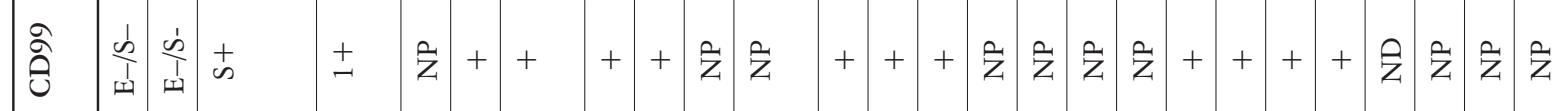

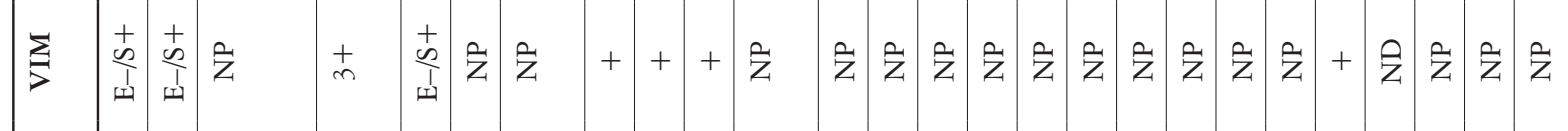

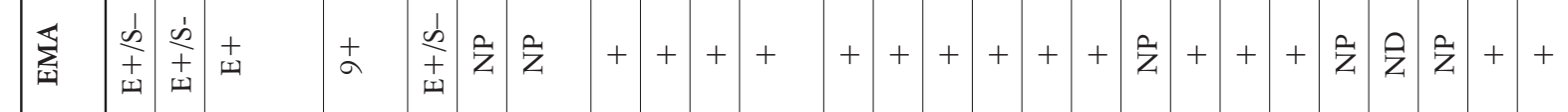

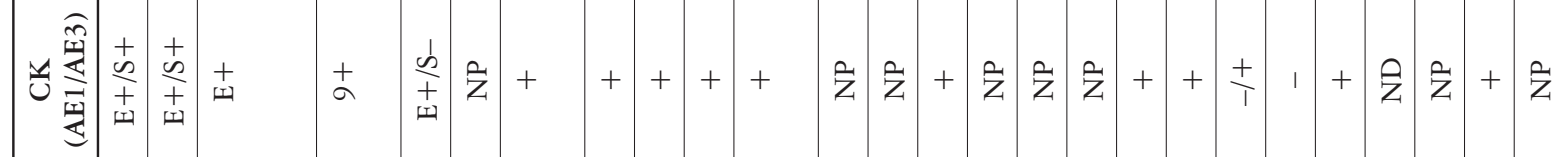

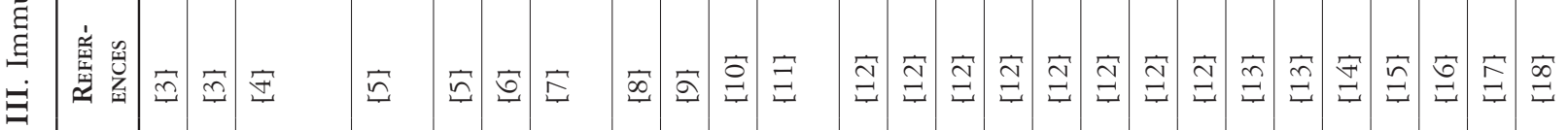

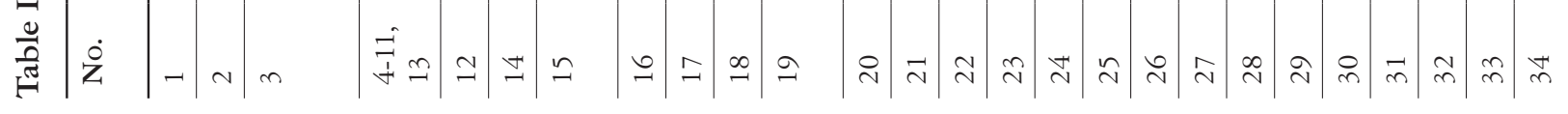




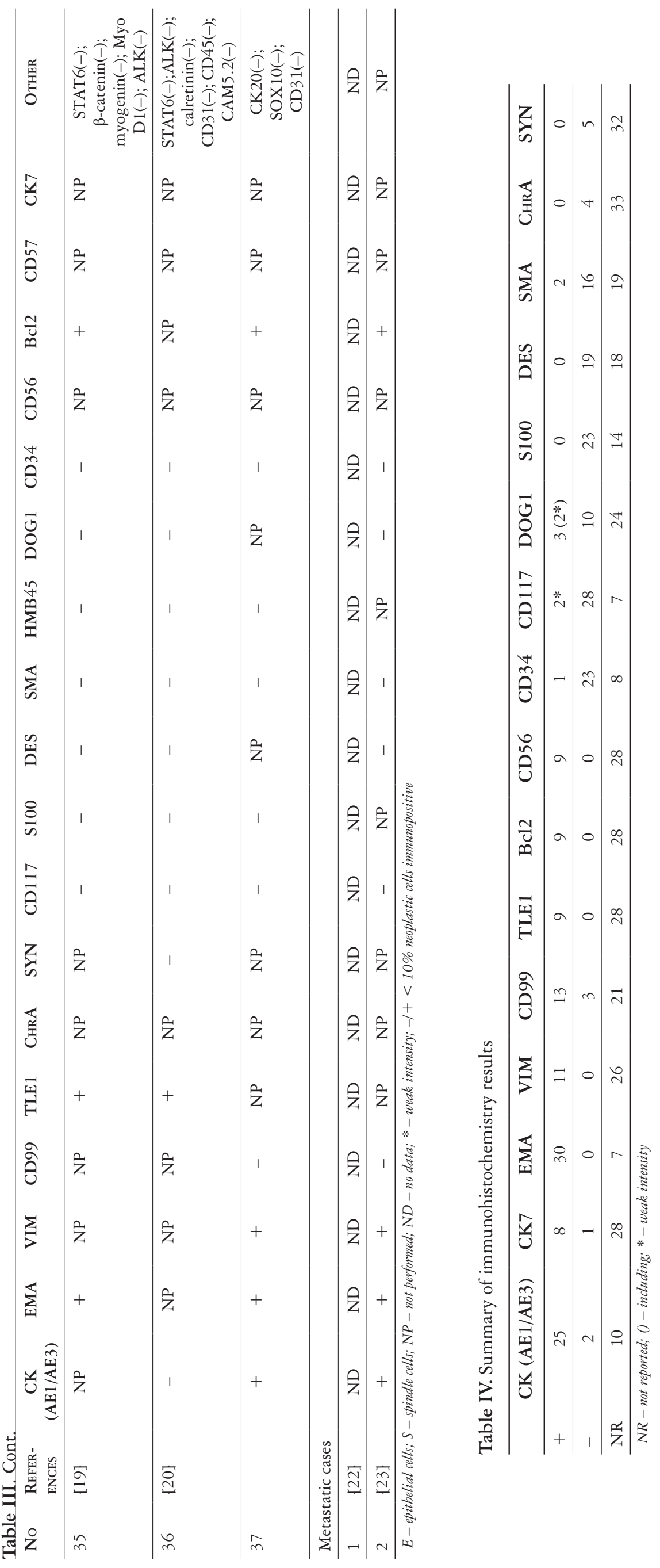


Table V. Synovial sarcoma of the stomach. Disease specific survival depending on the histological type of the tumor

\begin{tabular}{lccc}
\hline Histological subtype & Alive & Died & Total \\
\hline Monophasic & $19(95 \%)$ & $1(5 \%)$ & 20 \\
\hline Biphasic & $1(33.3 \%)$ & $2(66.67 \%)$ & 3 \\
\hline Poorly differentiated & $1(33.3 \%)$ & $2(66.67 \%)$ & 3 \\
\hline All & $21(80.77 \%)$ & $5(19.23 \%)$ & 26 \\
\hline & & & $\mathrm{p}=0.00352$ \\
\hline$\chi^{2}$ Pearson's coefficient & & $\mathrm{p}=0.00716$ \\
\hline$\chi^{2}$ NW & & & \\
\hline
\end{tabular}

A

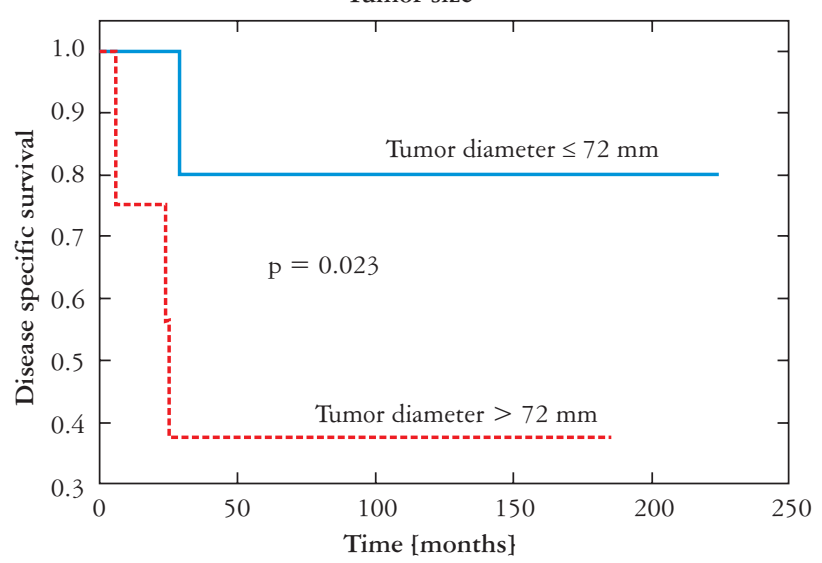

B

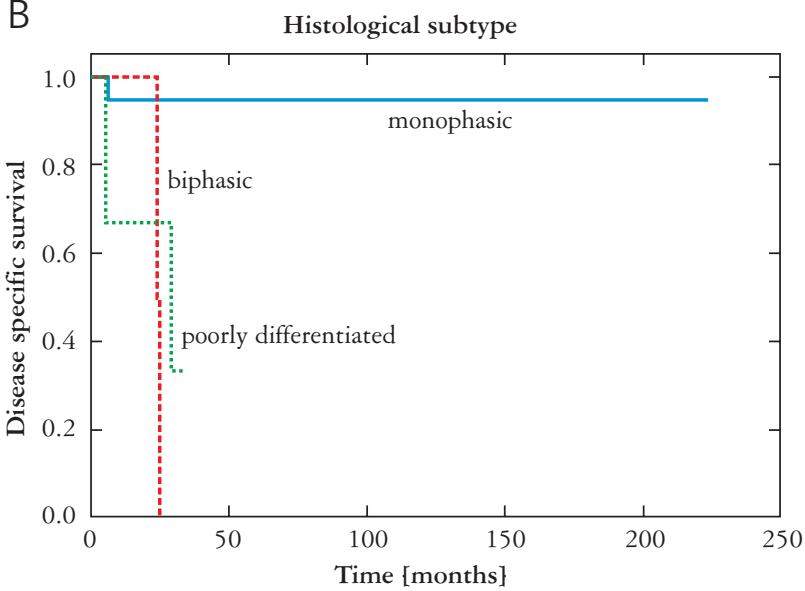

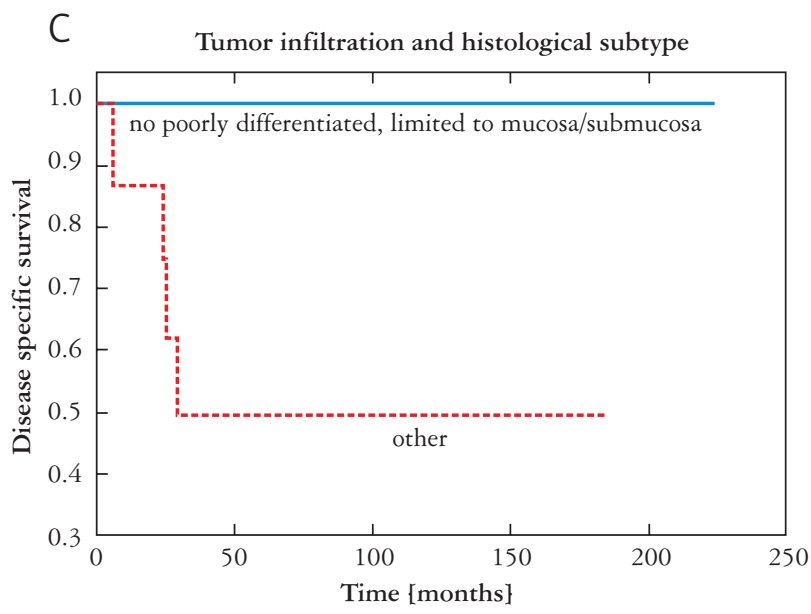

Fig. 11. Three morphological features affecting disease-specific survival of the gastric synovial sarcomas: A) tumor size, B) histological subtype of tumor, and C) depth of infiltration of the stomach wall together with a histological subtype of the tumor

plasm shows a haemangiopericytoma-like pattern and diffuse CD99 immunopositivity.

The mainstay of treatment for gastric SS is surgery, such as total or partial gastrectomy and wedge resection. All the reported cases, including our case, have undergone surgical resection. One (our) case has received neoadjuvant chemotherapy and other six cases have received postoperative chemotherapy; however, none of them has received radiotherapy.

Prognosis of SS in the gastrointestinal tract is unclear because of too small number of cases. The reviewed publications document six deaths, from which five were directly related to this disease. Two cases were defined as biphasic (tumor size 8 and $11.5 \mathrm{~cm}$ ), one belonged to monophasic subtype $(10 \mathrm{~cm})$ and 
other two had poorly differentiated component (one biphasic - $16 \mathrm{~cm}$; one monophasic $-2 \mathrm{~cm}$ ). Those deaths occurred between 6 and 29 months following diagnosis. One patient, with local recurrence, died of causes not related to the SS.

Survival analysis was carried out in the group of 26 patients for whom data concerning outcome and follow up were available. In this group 5 deaths were noted and all were caused by this disease. The median time of observation was 18 months and ranged from 2-224 months.

The mean tumor size in the group of patients who survived was statistically smaller that in the group of patients who died of disease $(52.6 \mathrm{~mm}$ vs. $95 \mathrm{~mm}$, $\mathrm{p}=0.049)$. We found out that patients with tumor larger than $72 \mathrm{~mm}$ had statistically significantly worse probability of survival $(\mathrm{p}=0.023)$ (Fig. 11A).

It seems that histological subtype can influence the prognosis. In the group of patients with monophasic subtype only one patient died (1/20), whereas in the group with biphasic or poorly differentiated tumors the percentage of deaths was significantly higher (Table V, Pearson $\left.\chi^{2} \mathrm{p}=0,004\right)$. These observations were confirmed by Kaplan-Meier analysis of survival (Fig. 11B).

Although there is no statistical significance, it was observed that in the group of patients who had tumor limited to mucosa or/and submucosa and without poorly differentiated component, the survival was $100 \%(\mathrm{p}=0.143)$ (Fig. 11C).

This shows that the tumor size and histological subtype of SS arising in the stomach are important prognostic factors.

Metastatic synovial sarcoma has been reported at least twice in the gastric wall (Table II). This was a case of a 49-year-old Japanese man who underwent chemotherapy and radiotherapy after amputation of his right leg for monophasic fibrous synovial sarcoma of the right calf. He developed multiple metastatic lesions in the stomach and duodenum; histologically similar to the primary tumor [22]. The second case was a 56-year-old male with primary synovial sarcoma of the left thigh with subsequent metastases to the stomach [23].

\section{Conclusions}

In summary, the primary gastric SS is a rare and underdiagnosed neoplasm. The awareness of occurrence of synovial sarcoma in the stomach may help to settle the proper diagnosis of tumor that should not be confused with other spindle cell and cytokeratin-positive neoplasms, as well as KIT-negative GISTs.

The authors declare no conflict of interest.

\section{References}

1. Hornick JL. Practical soft tissue pathology: a diagnostic approach, 2nd edition. Elsevier 2018.

2. WHO Classification of Tumours Editorial Board. Soft tissue and bone tumours. Lyon (France): International Agency for Research on Cancer; 2020. (WHO Classification of tumours series, 5th ed.; vol. 3). https://publications.iarc.fr/588.

3. Billings SD, Meisner LF, Cummings OW, Tejada E. Synovial sarcoma of the upper digestive tract: a report of two cases with demonstration of the $\mathrm{X} ; 18$ translocation by fluorescence in situ hybridization. Mod Pathol 2000; 13: 68-76.

4. Akhunji S, Musil I, Baisre de Leon A, et al. Synovial sarcoma arising in the gastric wall. Cancer Ther 2007; 5: 457-462.

5. Makhlouf HR, Ahrens W, Agarwal B, et al. Synovial sarcoma of the stomach: a clinicopathologic, immunohistochemical, and molecular genetic study of 10 cases. Am J Surg Pathol 2008; 32: 275-281.

6. Sinniah RP, Roche E, Cameron D. GI synovial sarcomas. Clin Transl Gastroenterol 2012; 3: e11.

7. Wang CC, Wu MC, Lin MT, Lee JC. Primary gastric synovial sarcoma. J Formos Med Assoc 2012; 111: 516-520.

8. Kamata K, Wada R, Yajima N, et al. Primary gastric synovial sarcoma: molecular diagnosis and prediction of prognosis. Clin J Gastroenterol 2013; 6: 303-308.

9. Sahara S, Otsuki Y, Egawa Y, et al. Primary synovial sarcoma of the stomach - a case report and review of the literature. Pathol Res Pract 2013; 209: 745-750.

10. Torres Rivas HE, Fernández S, Fresno MF. Primary gastric synovial sarcoma. Pathology 2014; 46: 253-256.

11. Michot N, Robert PE, De Muret A, et al. Gastric synovial sarcoma: case report and systematic review of literature. J Gastrointest Cancer 2014; 45 Suppl 1: 129-131.

12. Romeo S, Rossi S, Acosta Marín M, et al. Primary Synovial Sarcoma (SS) of the digestive system: a molecular and clinicopathological study of fifteen cases. Clin Sarcoma Res 2015; 5: 7.

13. Wong NA, Campbell F, Shepherd NA. Abdominal monophasic synovial sarcoma is a morphological and immunohistochemical mimic of gastrointestinal stromal tumour. Histopathology 2015; 66: 974-981.

14. So IT, Cho KB, Lee JY, et al. A primary gastric synovial sarcoma: A case report and literature review [published correction appears in Medicine (Baltimore) 2018; 97: e9742] [published correction appears in Medicine (Baltimore) 2017; 96: e9531]. Medicine (Baltimore) 2017; 96: e8904.

15. Ogino S, Konishi H, Ichikawa D, et al. Detection of fusion gene in cell-free DNA of a gastric synovial sarcoma. World J Gastroenterol 2018; 24: 949-956.

16. Olsen G, Beal EW, Pfeil S, Dillhoff M. Primary Gastric Synovial Sarcoma Mimicking a Gastrointestinal Stromal Tumor (GIST): Gastric Synovial Sarcoma. J Gastrointest Surg 2018; 22: 1450-1451.

17. Hu S, Wong K, Ramesh KH, et al. Diffuse, Aggressive Metastatic Progression after Minimally Invasive Local Resection of Primary Gastric Synovial Sarcoma: a Case Report and Systematic Review of the Literature. J Gastrointest Cancer 2019; 50: 116-122.

18. Fuente I, Bruballa R, Corradetti S, et al. Gastric Synovial Sarcoma. J Gastrointest Surg 2019; 23: 1515-1517.

19. Manohar A, Gopal C, Premalata CS, et al. Primary Gastric Synovial Sarcoma in a Child: A Case Report and Review of the Literature. J Pediatr Hematol Oncol 2020; 10.1097/ MPH.0000000000001688.

20. Wong HK, Law S, Collins R. Gastric synovial sarcoma: a case report and literature review. Hong Kong Med J 2020; 26: 142-145.

21. Miettinen M, Dow N, Lasota J, Sobin LH. A distinctive novel epitheliomesenchymal biphasic tumor of the stomach in young 
adults ("gastroblastoma"): a series of 3 cases. Am J Surg Pathol 2009; 33: 1370-1377.

22. Anjiki H, Yamamoto T, Ishii T, et al. Synovial sarcoma metastatic to stomach and duodenum. Gastrointest Endosc 2004; 59: 75.

23. Samuel T, Norly S, Ros'aini P. Gastric ulcer that turned out to be metastasis of a synovial sarcoma: A case report and literature review. Med J Malaysia 2016; 71: 363-365.

\section{Address for correspondence}

\section{Martyna Krupińska MD}

Department of Tumor Pathology

Maria Sklodowska-Curie National Research Institute of Oncology

Krakow Branch

Garncarska 11

31-115 Krakow, Poland

e-mail: martynakrup@gmail.com 